\title{
Sustaining student wellness in higher educational institutions: Possible design principles and implementations strategies
}

Author:
Karien Henrico ${ }^{1}$
Affiliation:
'Department of Emergency
Medical Care, Faculty of
Health Sciences, University of
Johannesburg, Johannesburg,
South Africa
Corresponding author:
Karien Henrico,
karienr@uj.ac.za
Dates:
Received: 01 July 2021
Accepted: 29 Oct. 2021
Published: 31 Jan. 2022
code with your
How to cite this article:
Henrico K. Sustaining student
wellness in higher
educational institutions:
Possible design principles and
implementations strategies.
J transdiscipl res S Afr.
2022;18(1), a1114.
https://doi.org/10.4102/
td.v18i1.1114
Copyright:
Co 2022 . The Author.
Licensee: AOSIS. This work
is licensed under the
Creative Commons
Attribution License.

Popular discourse identifies education as the cure for many of society's ills. However, surviving university is often seen as a period in which students face a unique array of challenges. Many students begin their tertiary education as holistically-well individuals, but due to the stressors related to University, students often show incremental signs of psychological, physical and emotional distress. These often lead to a decrease in academic competence and severe professional ramifications. The aim of this study was to identify design principles and explore the perceptions of professionals concerning possible implementation strategies that could be suitable for Higher Educational Institutions, particularly Health Science and Medical School students. A qualitative, three-phase multiapproach design was used in this study. Phase one was conducted by means of an explorative desktop literature review, there after phase 2 included a self-management, self-coaching and appreciative coaching concept map, that was aligned to concepts within the current individual wellness literature and in phase 3, Appreciative Inquiry based focus group discussions were held with various professional in the field of coaching, education, and healthcare. Wellness programmes are impacted by the fact that Higher Education Institutions face unique challenges such as time, financial constraints, and an already overloaded curriculum. Five design principles were described, and various implementation strategies explored. There is a fundamental necessity to address the distortion of wellness within HE. A key finding in this study suggests that combining self-coaching, appreciative coaching and self-management principles could facilitate a successful individual wellness programme for higher educational students.

Keywords: wellness; wellbeing; student wellness; higher education; individual wellness; wellness strategies.

\section{Introduction}

Both government and universities often profess that higher education (HE) benefits a nation economically, culturally, and socially. ${ }^{1}$ Investing in HE is seen as an investment in the human capital of a nation. ${ }^{2}$ For the individual, HE promises both social and economic benefits. ${ }^{3}$ It is associated with the development of personal capabilities and economic potential and is believed to considerably increase the earning potential of graduates. ${ }^{2}$ Literary contributors to the discourse have indicated that participation in HE often leads to an enhancement in an individuals' sense of life satisfaction, their sense of usefulness, their worth, their wellness and health. ${ }^{1,2,3}$

Attaining a HE qualification carries with it societal expectations of expert knowledge and improved competency within a professional practice. Therefore, graduates from departments within a Faculty of Health Sciences and Medical Schools are expected to provide high quality patient care that is compassionate, appropriate, effective, and individualised whilst demonstrating various interpersonal skills in an ethical and professional manner. ${ }^{4}$ These core competencies are written in almost all qualifications in some way or another, and are articulated by some in their writings about the concept of 'graduateness'. ${ }^{5}$ Furthermore, patients have alluded to the fact that they want health practitioners to additionally have a treatment strategy planned, be sincere, receptive, and calm, and listening courteously and be caring towards the patient. ${ }^{4}$

When entering HE, students often display varying degrees of emotional and physical health. This can be attributed to the challenges they faced during their schooling years. ${ }^{6}$ Students 
mostly display a normal expectation of how the programme they enrolled for, will prepare them for their chosen career. ${ }^{7}$ Students are most often of a healthy physical and euthymic state as they embark on their studies during their HE career. ${ }^{6,8}$ The World Health Organization (WHO) revealed that mental health accounts for $13 \%$ of the global disease burden, and that suicide is the second leading cause of death amongst 15-29-year-olds. ${ }^{9}$ The HE students are part of the most vulnerable group when considering issues of mental health, emotional disorders, and psychological problems. ${ }^{10,11}$

During their studies, a graduate student will face and cope with various psychological, personal, financial, and academic challenges in their own unique HE quests. ${ }^{3}$ Time constraints and financial burdens are commonly mentioned as the main sources of distress amongst students of HE. ${ }^{12}$ During the first few months of university, depression and anxiety related signs and symptoms increase, particularly for female students. ${ }^{6,8}$ A previous study conducted on Psychology, Medicine, Dentistry and Nursing students identified that $52 \%$ of students suffer from some degree of depression: 25\% suffer from mild depression, 19\% from moderate depression and an alarming $8 \%$ of study participants suffered from major depression. ${ }^{13}$ A more recent study on anxiety and depression concluded that medical students scored $61 \%$ higher for anxiety and $70 \%$ higher for depression during, what they call, the coronavirus disease 2019 (COVID-19) era. $^{14}$ A decline in mental health will negatively impact the student's academic outcomes. ${ }^{10}$ It was also noted that medical students presented with a higher percentage of depression than the other disciplines. ${ }^{10}$ It is well-documented that HE students face various academic challenges, however, one should also note that they often relocate geographically to attend university, and this often leads to a loss of social support and feeling of isolation. ${ }^{6}$ The predicaments students face impact their overall wellness. According to the $\mathrm{WHO}$, wellness is defined as: 'a state of complete physical, mental and social well-being and not merely the absence of disease and infirmity ${ }^{\prime}{ }^{14}$ Adding to the perplexity of student wellness, is the fact that many of them are suddenly living in and are exposed to socially stimulating environments which could create an environmental discrepancy for them. ${ }^{15}$ If student wellness is lacking, the outcomes could be absenteeism, desertion or even suicide. ${ }^{13}$ Literature describes a range of existing strategies aimed at addressing the current wellness challenges within HE. However, the researcher is of the opinion that currently no concurrent consideration exists to address this misalignment of wellness initiatives in HE. ${ }^{10,16,17}$

\section{Achieving wellness: Awareness or sustained behaviour modification?}

The demands on both the student and the university within a 21st century setting is ever changing, even more so in the current COVID-19 era, ${ }^{14}$ innovative wellness education methods therefore are imperative for today's fast paced society.,12 Numerous academic articles have tried to address the issues related to introduction of wellness initiatives into the current curricula of health professionals, which is riddled with time, financial and staff capacity confinements. ${ }^{8}$

Most HE institutions have various wellness strategies they offer their students, all with a common goal of achieving a sense of wellness. ${ }^{18}$ Teaching wellness strategies during formal training brings noteworthy benefits for the HE students. ${ }^{16}$ These benefits amongst other include: positive emotional, physical, mental, interpersonal change, and improved academic performance, to mention only but a few. ${ }^{16,19}$ Higher Educational educators have the responsibility to send informed and accountable citizens into the workplace, such citizens should perceive wellness as a lifetime commitment. ${ }^{15}$ Academia needs to facilitate and initiate the internalisation of the lifelong learning processes that is fundamental to achieving a state of wellness. ${ }^{7,18}$ Even if HE students and educators value the importance of wellness initiatives, it is challenging for curriculum committees and administrators however to assign faculty resources to such programmes. ${ }^{6}$ Literature suggests that strategies aimed at improving wellness can be taught, however education alone does not promote the behavioural change needed to achieve a high level of wellness. ${ }^{7,20}$ Simply understanding wellness, and the associated terms and concept, does not automatically translate into the individual being 'well'. ${ }^{10,15}$

The acknowledged benefits of wellness education in HE settings are validated by several scholars in relation to the place, intended purpose, and impact of wellness strategies and courses. ${ }^{8,10,12,18}$ When wellness initiatives and methods are taught in HE courses, students are offered opportunities to learn various skills and strategies that can be applied both in the classroom and beyond.

Many HE institutions offer extra-curricular wellness initiatives, such as counselling, and wellness strategies through student affairs and student life services. ${ }^{8}$ These are valuable but there is a call and need for more inclusive and holistic wellness education within the curricula. ${ }^{8,21}$ Wellness education, to some extent, is included in a few curricula activities. ${ }^{17,22}$ Although wellness training programmes aim at teaching HE students to recognise and alleviate the adverse effects of burnout and trauma, many students may not receive the knowledge and skills associated with promoting their own holistic professional and personal wellness. ${ }^{8,22}$ Holistic wellness initiatives will best benefit HE students if it allows for behavioural modification, is multidimensional, interconnected, and supports lifelong wellness learning., ${ }^{7,16,23}$ When preparing a wellness courses for undergraduate students, in particular, traditional face-to-face interactive sessions, time-consuming workshops, and individual consultations might not be suitable or feasible, because of the current overloaded curriculum. ${ }^{24}$ Students should be encouraged to pursue life-long wellness education and chose to actively participate in and be accountable for their unique or individual wellness journey.,21,25 
Developing lasting strategies that emphasises wellness and various prevention strategies through a personal responsibility for one's health is the only reliable way to prepare an individual for the challenges mentioned previously and additional challenges that might be encountered in the future. ${ }^{3,7,21}$ When students deliberately engage in wellness preparation, education, evaluation, and assessment, they will foster their own wellness despite the challenges associated with being a HE student. ${ }^{8,16,22}$ When wellness is cultivated at the student level, stressors associated with pursuing their education will likely be reduced. ${ }^{8,15}$ When holistic wellness approaches are internalised and learned, students will experience substantial benefits such as positive emotional, physical, intellectual, interpersonal, and attitudinal changes. ${ }^{19}$

Given the well-recognised importance of wellness, it would seem sensible for employers to request holistic wellness training for HE's and seek out 'well' graduates as their chosen future workforce. ${ }^{21,26}$ Just as any organisation needs to provide an atmosphere that promotes wellness and offer wellness initiatives, similarly academia should cultivate wellness amongst its staff, students, and graduates. ${ }^{15,21}$ Engaging staff and students in wellness has always been important. But in the current COVID-19 pandemic climate, it is imperative that HE institutions (HEIs) creates an ethos that promotes wellness and personal responsibility through behavioural modification.,21 Literature has suggested that if HEIs fail to address the student wellness, they will face a crisis that will lead to a reduction in both pass rates and retention rates. ${ }^{12}$
This study was designed to identify design principles and explore the perceptions of professional experts concerning possible implementation strategies that could be included in a holistic individual wellness programme suitable for HEIs, in particular Health Science and Medical School students. By doing so, this study theorises on design principles and allows for implementation of theory. Design specifications are collections of ideas about the essence of HE wellness initiatives and provide information needed to initiate wellness. ${ }^{27}$ The term 'design principles' is used to identify the kind of prescriptive theoretical understandings developed through this study ${ }^{27}$; this kind of theory includes predictive, explanatory and descriptive understandings that guide the formulation of a proposed wellness initiative. The primary research question focused on identifying draft design principles for holistic individual wellness initiatives and exploring ways in which universities could efficiently implement holistic individual wellness strategies based on the suggested draft design principles.

\section{Methodology}

This study utilised a three-phase multi-approach qualitative design. Figure 1 offers a pictorial overview of the study phases.

During phase one of this study, data was collected via an explorative desktop literature review. This provided a contextual understanding of the concepts identified (see Figure 1), and also provided a supportive understanding to

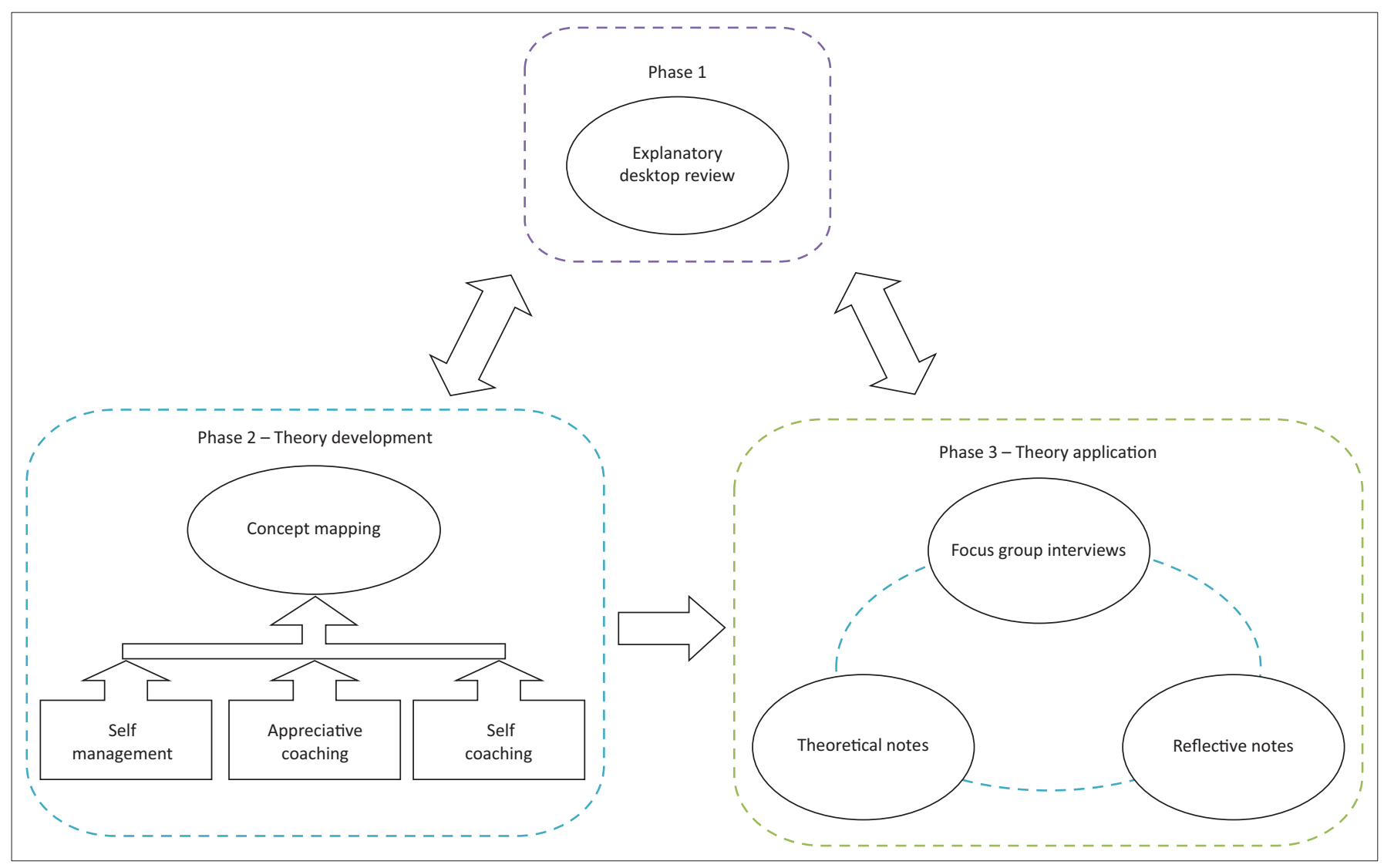

FIGURE 1: Schematic representation of the study phases. 
the focus group discussions (FGDs). Numerous sources were included such as journal articles, books, and other relevant publications on Medline, Embase, CINAHL, EBSCOhost, Web of Science and Cochrane databases. A health sciences librarian was consulted to provide guidance on the search strategy and identify the various individual wellness terms and Boolean phrases that were used. The focus of the literature review was, however, individual wellness within the context of health sciences and health, or medical, professionals. Individual wellness was chosen as the wellness strategy, because of its holistic, individualised nature of individual wellness. ${ }^{19}$

Phase two consisted of a self-management, self-coaching and appreciative coaching concept map, ${ }^{28}$ and aligning these concepts with the results of the in-depth explorative desktop review. The researcher is of the opinion that using selfmanagement $t^{29,30}$ and self-coaching ${ }^{31}$ strategies within a wellness programme might address the individualised nature needed for holistic wellness. And if a future wellness programme builds on the coaching style associated with self-coaching and appreciative coaching, ${ }^{32}$ it might overcome the time and financial constraints currently associated with HE. Phase one and two focused on answering the following research question: 'What draft principles should be included in a holistic, individual wellness programme suitable for HE?'.

In phase three, data was obtained through appreciative inquiry $(\mathrm{AI})^{33}$ based FGDs $(n=2)$, which were part of a larger scale qualitative design-based research study. ${ }^{7,27}$ The focus groups (FGs) were conducted to listen to and gather information from the participants. ${ }^{34}$ The FGs allowed the researcher to comprehend how the participants feel or think about implementing holistic individual wellness through a form of focussed discussion. The AI was used to phrase the questions used within the FGD; each question focussed on a phase of $\mathrm{AI}$ as described in the 4-D Cycle of $\mathrm{AI} .{ }^{35}$

The target population for phase three comprised of professional experts such as coaching experts, educational experts, university educators and qualified health professionals residing within two metropolitan cities in the Gauteng province of South Africa. Participants were conveniently sampled and invited to participate. As a result of the small number of participants available within the target population $(n=11)$, two FGs were conducted with seven participants in FG one and four in FG two

During each FG, a multi-topic discussion was facilitated. The discussion focussed on the indivisible self, evidence model for wellness (IS-Well), ${ }^{29}$ the concept map (that aligns with the outcomes of both phase 1 and 2 of the study), and the implementation of a holistic individual wellness programme. This article reports only on issues that related specifically to one of the open-ended questions that participants within the FG considered: 'How can universities efficiently implement holistic individual wellness strategies?'.
Additionally, the researcher used theoretical and reflective notes to ensure triangulation as a form of rigour and transparency in this qualitative study. ${ }^{7}$ Observations from the FG were written down by the researcher in the form of theoretical notes, this was done as any form of observation is loaded with theory. ${ }^{30}$ Reflective notes were written in the form of a reflective diary to meet the ethical, methodological, and emotional challenges associated with conducting qualitative research. ${ }^{31}$ These reflective notes were continuously written throughout the process of this research study and explored the experience of the researcher and the meaning of how the data represented itself. ${ }^{31}$ Open coding was used to analyse the data ${ }^{32}$ through the seven steps of Tesch's data analysis method. Thereafter, the researcher met for a consensus discussion with an independent coder who had experience in qualitative data analysis. Strict ethical and trustworthiness principles were adhered to during the course of this study. ${ }^{36}$

\section{Ethical considerations}

Ethical clearance was obtained from the University of Free State Research Ethics Committee (NHREC Registration number: REC-230408-011) and Higher Degrees Committee (HDC), ECUFS NR 45/2013.

\section{Results and discussion}

This article first attempted to identify design principles that will direct initiatives to improve the wellness of HE students through the explorative desktop review. Next followed the results that emerged from the explorative desktop literature review and the concept map for wellness programmes, and finally the FGDs and the explanatory desktop review were structured around four themes, namely, (1) intense future dream; (2) realistic HE implementation for students; (3) possible implementation obstacles, and (4) implementation guidelines specifically for the HE context.

The results that emerged from the explorative desktop literature review and concept map for wellness programmes were the five draft design principles. The data obtained in the first two phases of the study indicates that wellness initiatives, aimed at HEIs, in particular Health Sciences and Medical Schools, should be 'holistic, unique, flexible, adaptive, and effective'.

\section{Holistic}

Wellness is a holistic, multidimensional way of life that assists an individual to become conscious about and make decisions towards their optimal health and well-being. ${ }^{6,12}$ To achieve a sense of individual wellness, it is vital that wellness initiatives are holistic and incorporate the holism philosophy of wellness. Wellness initiatives should be an 'interconnected journey that aims to balance all the dimensions of wellness and manifest a relationship between various wellness factors and/or dimensions ${ }^{\prime} .{ }^{7}$ Additionally, balance is vital to achieve a sense of wellness; therefore, all dimensions of wellness 
need to be included in a proposed wellness programme. All areas of the mind should also be included in wellness initiatives. ${ }^{7}$ It seems that the conative wellness connection is often excluded in wellness programmes aimed at HEIs. ${ }^{35}$ Continuous self-reflection on the individuals' current and future wellness approaches could foster balance between all the wellness dimensions. Also, self-management skills and strategies should be included and nurtured. ${ }^{7}$

\section{Unique}

Wellness initiatives aimed at HEIs must be unique for each individual. Wellness initiatives must facilitate wellness for individual students and should consequently be as unique as the individual. The researcher would like to argue that wellness initiative has to first identify the level of wellness the individual is at, and then address their own wellness imbalance. To ensure optimal wellness, any proposed wellness initiative has to 'be personal and fit the lifestyle of the individual student' ${ }^{\prime, 15}$

\section{Flexible}

Wellness is not static, and therefore wellness initiatives are required to be flexible. Individual students will continuously identify and re-identify their own wellness needs. ${ }^{7}$ These needs might even change from time to time during the wellness journey. It is important that wellness programme participants actively engage in the programme, to kindle their 'positive core' and continuously improve their selfmanagement, self-care, and self-improvement tactics. Wellness programmes should also allow room for expected development, maturity, and transformation in dealing with the challenges an individual is exposed to in his or her lifetime. People will naturally, as they journey through life, become more mature in how they face unanticipated challenges. It is therefore vital that wellness initiatives and programmes respond to these changes that everyone will bring along with them. ${ }^{7}$

\section{Adaptive}

Wellness relies on context. Hence, wellness initiatives should also be context appropriate and suitable for each participating student with their own contextual predicaments. ${ }^{7}$ Wellness initiatives should allow the individual, who participates, to successfully implement wellness strategies within his or her own unique circumstances. Wellness initiatives needs to facilitate behavioural change (hence the strong focus on selfmanagement and $\mathrm{AI}$ in this study). ${ }^{23}$ When focussing on changing behaviours, perseverance, considerable amounts of time, goal achievement, introspection, and unceasing participation is necessary. ${ }^{7,20,23}$ Wellness programmes should teach individuals to observe and make note of their own behaviour and feelings.

\section{Effective}

The final draft design principle identified in this study is efficacy. During the explorative desktop study, it became clear that wellness initiatives should be time and costeffective to allow implementation at HE HEIs, in particular Health Sciences faculties and Medical Schools. Initiatives aimed at improving wellness should be accompanied by guidelines for cost-effective and sustainable programme that facilitate individual wellness. ${ }^{7}$ This will meet the need for teaching wellness strategies and initiatives within the confinements of an HE context. The overarching aim of wellness initiatives is to maximise individual well-being and adopt lifelong wellness approaches. ${ }^{7}$

The four themes that resulted from the FGDs and the exploratory desktop review, namely (1) intense future dream; (2) realistic HE implementation for students; (3) possible implementation obstacles, and (4) implementation guidelines specifically for the HE context are discussed next, linked with the excerpts from the researcher reflective notes or verbatim transcripts of the participants $(\mathrm{P})$.

\section{Intense future dream}

The AI focuses on the positive core and discovering potential, hence the discussion allowed participants to dream about individual wellness within HE. ${ }^{35}$ The experts who participated in the FGD had an intense future dream for individual wellness as mapped out in phase 2 of this study. As seen in the following excerpt from the researcher reflective notes the participants broadened the original thinking of the researcher:

'I think I felt a reduction in my excitement towards the [study], but after conducting the focus group discussions, I felt a sense of "being alive" again. I saw a brighter future, more possibilities and even a higher sense of enthusiasm. One I have not felt in a very long time... Having experts in the field affirm your thinking and dreaming with you, is truly an improving, enriching, and empowering experience, that surpasses anything I could ever have imagined.' (Researchers reflective notes)

Participants dreamed that a wellness programme based on the concept map from phase 1 and 2, be included in the first year of HE studies:

'I think my biggest dream that [for holistic wellness] ... hmm ... this programme is done within the first-year student.' (Participant 3, Focus Group 2, Coaching Expert)

It is important to note that the vision held by the FG participants for including individual wellness within HE was not only limited to a health-related curriculum. This could be attributed to the perceived possibilities that this approach offers the individual in achieving what they wanted to achieve in the onset of their wellness journey:

'I think my dream will also be possibilities you know, the possibilities that is there in the programme ... whatever programme, nursing, emergency medical care ... what are the possibilities for me to be able to achieve what I want to achieve you know, because everybody is not being taught about, you know, self-management and things like that.' (Participant 1, Focus Group 1, Health Professional) 
As seen above, not all HE students are taught individual wellness and self-management related topics that allow them to internalise their own well-being 'toolkit'.,37 Literature clearly suggests that that holistic individual wellness and self-management are currently not used efficiently in HE. ${ }^{7,17,38}$ By including a holistic wellness and self-management programme that is built on the five draft design principles, in $\mathrm{HE}$, the student will be able to identify how their future professional career and personal wellness, could be. The following excerpt clearly identifies a reason for including the individual wellness as mapped out with the relevant concepts within any course:

'[... S]tudents will already be able to say that within [a health domain], where do I want to be so that in the next year as they build themself a brand and find themself a place, it becomes a very focus almost specialised decision, because our problem is that at any point time as we were developing to be these [care providers] we were not sure in terms of when I finished I'm going to work in a specific hospital or private practise, you know and that sort of thing. And I found that that sort of reduce the extent to which we development our careers.' (Participant 5, Focus Group 1, Health Professional)

Allowing students to envisage where they want to position themselves within their chosen industry will allow them to enable the progression of their careers. ${ }^{7}$ This might be because they will be more fixated on their future from the commencement of their HE studies.

\section{Realistic higher education implementation for students}

Experts who participated in the FGDs expressed that individual wellness could be implemented within HE. Participants identified a deficiency in teachings on individual wellness and self-management strategies during their own formal training. ${ }^{7}$ This view agrees with current literature. ${ }^{6,8,16,17,21,39}$ As seen in the following quote, the absence of wellness strategies could be in part because the healthcare providers are often viewed as 'being okay'. ${ }^{7}$ It seems as if there is a distinct imbalance between knowing what is professionally expected and coping within a healthrelated domain: ${ }^{6}$

‘Because I doubt well ... hmm ... definitely not while I was training ... hmm ... the value of something like this ... hmm ... was not even touched upon ... hmm ... you knew what is expected of you, but not exactly how to cope with it, or maybe it's because most people that are therapist are service-orientated people so they are always looking after others, and they tend to ... a ... think that they are okay and ... a ... maybe because that attitude ... hmm ... it was never brought into as a study, because I mean why would you need that because you are always okay....' (Participant 3, Focus Group 3, Educational Expert)

Therefore, to effectively implement individual wellness within HE, participants feel that the best time to incorporate such a programme would be within the first few weeks of First-Year studies.

'[...W]ere they starting that first week, that we sort of break it down for them. You can divide into six stages in six weeks in each week just right there at the beginning because I find that as you know.' (Participant 1, Focus Group 2, University Educator)

The example given by the participant above, of separating a proposed programme into several weeks, each focusing on a principle or wellness dimension might be a feasible and simple way to introduce individual wellness into an academic programme. $^{7}$

Another implementation strategy shared by participants is to include the proposed programme as a prescribed module:

'I just think that it is that is done, that we can have this in a module, that there is now a way that you can continue to pursuit self you know self-interest, because you then realise how you affect the bigger picture.' (Participant 7, Focus Group 1, Educational Expert)

Including individual wellness as a prescribed module might be ideal, however this might not be a viable option for all courses. The researcher believes that this could be challenging, as Health Sciences and Medical curricula are generally already overloaded. ${ }^{6,717}$ If an individual wellness programme can be implemented as a module, it would facilitate reflective strategies that are important for the successful implementation of individual wellness programmes, as seen below:

'At least go through the programme and force a reflective stage. You know, at the end of every term you have to sit with your dream buddy and go through it and just say where are you know, to check yourself, even if it is not in the course.' (Participant 2, Focus Group 2, University Educator)

Implementing a holistic individual wellness programme during the first few weeks of first-year studies, would be the best route for success. As the following quote demonstrates, an individual wellness programme should be included during formal education:

'But at least, if it is going to be for [health care], at least during the course.' (Participant 1, Focus Group 1, Health Professional).

There is a maldistribution of holistic individual wellness and self-management strategies within HE. It is also pertinent that HEIs do not ignore self-management and wellness strategies in the 21st century. ${ }^{7,8,12,21}$ Therefore, the successful implementation of holistic individual wellness and selfmanagement programmes and initiatives within HEIs is vital. ${ }^{11}$

\section{Implementation obstacles}

The third theme discussed by the FG participants were possible implementation obstacles. To ensure successful implementation of a holistic individual wellness initiative in any HE curriculum, it is also important to anticipate implementation obstacles that might hamper flawless execution of the proposed initiative.

The first obstacle that needs to be considered is the way in which individuals learn and at what stage of change they are when they are introduced to the individual wellness 
concepts and dimensions. The following two quotes identify that some individuals will wholeheartedly participate in a wellness programme whereas some will only 'dabble' superficially in the intended programme, where some might not engage with the programme at all. Hence, the stages of change, ${ }^{23,40}$ Maslow's Hierarchy of needs, ${ }^{41}$ and adult education principles ${ }^{36}$ should be included when planning possible implementation guidelines for a holistic individual wellness programme:

'Some people will receive it, some people will learn it and some people won't ... and that's just unfortunately life.' (Participant 4, Focus Group 1, Coaching Expert)

'[... S]ome will dabble on the surface and some might go further and some might not engage in, in it at all because they are not reflective by nature or not interest so ... hmm ... but I think that is a very valuable input.' (Participant 2, Focus Group 2, Health Professional)

Another implementation obstacle that the participants reflected on is excitement level that a proposed individual wellness programme evokes within the student. If people get enthusiastic about a programme and the wellness opportunities offered by such a programme, personal engagement will be on a deeper level. It is perceived that during the introduction stage of any holistic individual wellness programme, a strong emphasis should be placed on the life-giving and positive facets of AI:

'I think it's incredible but ... hmm ... I think something that would just maybe ... uhm ... be worth looking at is how to get people excited about a programme, like if they know nothing about something like that. They do have a problem and they are going nowhere slowly ... Hmmm ... in personal wellness, but how to get them to understand a programme like that if they have no idea.' (Participant 6, Focus Group 1, Coaching Expert)

Lastly, FG participants predicted that the various levels of basic human needs that the individual presents with, education level and point of departure, might impact the implementation of a holistic individual wellness initiative. As the following quote illustrates, using Maslow's Hierarchy of basic needs could permit a proposed programme to appeal to numerous individuals who are all starting at different stages of basic needs:

' $[\ldots H]$ ow do you sell it to different levels of self ... those with educational background might have insight and it's easier, than the one ... if I think of Maslow's Hierarchy, you know where they ... at the basic needs, taxi money, isn't at the level where you are going to sell this to. So different levels would probably require different approach. Selling it to a manager it would quite different from implementing it in an educational setting, for instance higher education.' (Participant 4, Focus Group 2, University Expert).

Although FG participants did not mention it, the researcher is of the opinion that the amount of support and commitment a proposed wellness initiative receives from lecturers and management could potentially affect the implementation success of a holistic individual wellness initiative. If there is a little to no executive support, there will be a direct impairment in the successful implementation of an individual wellness initiative amongst students. Thus, having full support of the managerial team when aiming to implement an individual wellness programme in any educational setting it vital for its success.

\section{Implementation guidelines}

The final theme that emerged from the study was several implementation guidelines. Both the researcher and the study participants are of the opinion that including an individual wellness programme during first year orientation might be appropriate for the health professional context. Because of the current limitations on time, the availability of resources and the high demand on student commitment, a few half-day sessions during first-year orientation might be the most suitable suggestion. Throughout the intended sessions, participating student should be engaged in an individualised manner. Monthly group session could also prove a good add on to ensure implementation success.? Utilising departmental tutors as wellness tutors and/or mentors might also be an appropriate way to implement holistic individual wellness initiatives in the HE context. ${ }^{42}$

Volunteering senior students might be best suited to act as wellness tutors who mentor first-year students. These mentors would first be trained on all aspects and dimension associated with the proposed individual wellness programme prior to their appointment. ${ }^{7}$ There should be at least one wellness mentor or tutor per academic department, depending on the amount of first year students they take in. The wellness tutor has to be introduced to the first year students at the start of the orientation and be present during the duration of the orientation. It is recommended that the tutors make themselves available for individual sessions during the academic year. Follow-up sessions should be arranged with students to track their progress during each term in the academic calendar. ${ }^{42}$ These sessions could be conducted in a group format and might strengthen a collaborative network that is needed for successful implementation of an individual wellness programme based on the five draft design principles discussed earlier.

A study conducted by Ramrung, ${ }^{48}$ determined that a student mentorship programme is effective in enabling the participating student to gain an improved understanding of a holistic wellness programme and a better understanding of the student's self, their unique goals, and their morals. ${ }^{41}$ Ramrung also indicated that scaffolding a mentorship programme could facilitate the soft skills students need to achieve success in their time at university, this includes timemanagement. ${ }^{41}$ Using a similar methodology to implement a holistic individual wellness tutor or mentor programme, might suit the context of most health professions disciplines.

If educators fail to facilitate the wellness of students during their formal training, 'students may lack skills to self-heal in response to professional distress'. ${ }^{16,22}$ When wellness initiatives allow educators to support professional 
self-care and monitoring such activities, educators could potentially encourage various career supporting behaviours that are related to high levels of individual wellness. ${ }^{8}$ As mentioned earlier wellness can be learned, and when it is learned various issues associated with somatisation, psychoticism, and interpersonal sensitivity might be reduced. ${ }^{15}$ The success of individual wellness initiatives will be greater if educators give students authentic opportunities during their formal training, to practise and improve their own self-regulation strategies. ${ }^{18}$ These authentic opportunities should be three-fold: (1) it should comprise learning tasks that permit scope for selfdetermined outcomes, (2) it should allow the student to recognise principles of effective learning that best suit their learning style, and (3) should include various strategies to achieve a sense of wellness. These components should be arranged according to each individual student needs and not in a generic way. ${ }^{8,18}$

Improving the perceived wellness level of a student during their formal training will help to encourage wellness practices early on. This in turn might reduce issues that could risk individual's wellness and professional competence later on in their career.,19 As mentioned earlier, education and learning about wellness interventions are important, however, more interventions are needed to ultimately change the participating student's behaviour ${ }^{20,23}$ and commence the process of lifelong learning, which is fundamental for achieving ultimate wellness. ${ }^{18}$

Authors have stated that is inappropriate for HE to not provide students with a wellness understanding and a skill set that will allow them to practise wellness as part of their 'tool chest' when registering for their chosen course. ${ }^{15,16}$ Considering the importance of wellness on the high return on investment for organisations, it seems sensible for future employers to request that HE students undergo wellness education during their time at universities and pursue graduates who possess wellness competences as future employees - similar to graduate characteristics of teamwork, leadership, creativity, adaptableness, etc. ${ }^{7,10,21,26}$ Not only should corporations provide an environment suited to wellness promotion, but HEIs must encourage holistic individual wellness amongst its staff and students.,15,21 When companies seek out 'well' graduates they will reap the rewards of enhanced performance that is associated with optimal levels of wellness. ${ }^{7,10}$ All HEIs should have a lasting healthcare strategy that builds a healthier student body and a strategy that promotes powerful ethos of wellness. ${ }^{16,21}$ There is a dire need for an individual wellness framework that connects (1) the learner's perspectives and wellness starting point, and (2) the current extra-curricular wellness activities offered by the university within holistic individualised wellness education model that is based on the five draft design principles. ${ }^{16,18}$ To date, no wellness model could be traced that incorporates such a holistic, individualised, approach for both the individual and university that fits within the HE context and meets needs for wellness education within the constraints of the $\mathrm{HE}$ system. ${ }^{7,17,18}$ Most of the wellness programmes and initiatives aimed at HE wellness education still focus on isolated variable of wellness and not the holistic approach needed for individual wellness. . $^{10,11,16,17,23}$

\section{Conclusion}

During the FGDs with the health profession experts, it became clear that addressing the misalignment of wellness within HE is of utmost importance especially in the current pandemic climate. The need to implement a holistic individual wellness programme, based on the five draft principles, that facilitates behavioural change is vital for both academic and professional success of HE students. Combining self-coaching, appreciative coaching and selfmanagement might be a novel approach to facilitate an individual wellness within the complex context of HE programmes. Participants in this study particularly affirmed the pragmatic approach of these methods as a result of their self-driven nature, preventative nature, flexibility, and emotional stability these methods allow within a wellness programme aimed at HE institutions.

\section{Limitations}

As with all research studies, this study is not without limitations. The perspectives of both undergraduate and post graduate students were excluded, as it was not possible to interview them. Their voices were included at a later stage of thelarger qualitative design-based study. Theimplementation strategies emerged from the opinions of professional expert and cannot be generalised and needs to still be tested as an implementation strategy for a holistic wellness model. Additionally, the researcher added personal opinions in the form of reflective notes to the discussion above and invites other researchers to respond to the suggestions of this manuscript.

\section{Acknowledgements}

The author acknowledges the participants for giving up their valuable time to participate in the study.

\section{Competing interests}

The author has declared that she has no financial or personal relationships which may have inappropriately influenced her in writing this article.

\section{Author's contributions}

The author declares that she is the sole author of this research article.

\section{Funding information}

Funding was received from the Health \& Wellness Sector Education and Training Authority (SETA) for the larger PhD Study. 


\section{Data availability}

The data that support the findings of this study are available from the author, upon reasonable request.

\section{Disclaimer}

The views and opinions expressed in this article are those of the author and do not necessarily reflect the official policy or position of any affiliated agency of the author.

\section{References}

1. Ryan T, French S, Kennedy G. Beyond the iron triangle: Improving the quality of teaching and learning at scale. Stud High Educ [serial online]. 2021 [cited 2021 Aug 17];46(7):1383-1394. Available from: https://0-web-a-ebscohost-com.ujlink.

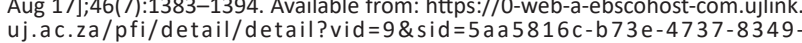

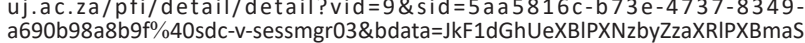
1saXZI\#AN=56823500\&db=eoah

2. Hughes K. The social inclusion meme in higher education: Are universities doing enough? Int J Incl Educ. 2015;19(3):303-313. https://doi.org/10.1080/13603116. 2014.930518

3. Corredor J, Álvarez-Rivadulla MJ, Maldonado-Carreño C. Good will hunting: Social integration of students receiving forgivable loans for college education in contexts of high inequality. Stud High Educ. 2020;45(8):1664-1678. https://doi.org/10.108 0/03075079.2019.1629410

4. Scheffer C, Paula Valk-Draad M, Tauschel D, et al. Students with an autonomous role in hospital care-patients perceptions. Med Teach. 2018;40(9):944-952. https://doi.org/10.1080/0142159X.2017.1418504

5. Nabulsi N, Mcnally Prince B, Bin M, et al. Improving graduateness: Addressing the gap between employer needs and graduate employability in Palestine. Educ Train. 2021;63(6):947-963. https://doi.org/10.1108/ET-06-2020-0170

6. McGrady A, Brennan J, Lynch D, Whearty K. A wellness program for first year medical students. Appl Psychophys Biof. 2012;37(4):253-260. https://doi. org/10.1007/s10484-012-9198-x

7. Henrico K. An appreciative self-management coaching programme to facilitate the wellness of somatology therapists. Bloemfontein: Universtiy of Free State; 2015.

8. Johnson J, Bauman C, Pociask S. Teaching the whole student: Integrating wellness education into the academic classroom. Student Success. 2019;10(3):92-103. https://doi.org/10.5204/ssj.v10i3.1418

9. World Health Organization (WHO). Mental health [homepage on the Internet] 2019 [cited 2021 Oct 13]. Available from: https://www.who.int/health-topics/ mental-health\#tab=tab_2

10. Amawulu E, Prosper KE. Mental health status of students attending tertiary institutions in Bayelsa State, Nigeria. J Public Health Epidemiol. 2018;10(10):363-369. https://doi.org/10.5897/JPHE2018.0999

11. Jung $C$. Why does it take a pandemic to see the real pandemic - Mental Health? Vol. 15. Pretoria: Arbinger Institute, BioMed Central Ltd., 2021; p. 1-3.

12. Maharaj A. Wellness factors impacting student academic performance from a higher education perspective [homepage on the Internet]. Educor Multidisciplinary
Journal, 2018 [cited 2019Jul 12]; p.69-85. Availablefrom: http://0-web.b.ebscohost. com.ujlink.uj.ac.za/ehost/pdfviewer/pdfviewer?vid=0\&sid=99e91b72-b83d-451acom.ujlink.uj.ac.za/ehost/pdfviewer/pdfvi
b2d1-b3f8d3a67552\%40pdc-v-sessmgr02

13. Ortega RFF, Barros AC, Cantero OH. Depression and socio demographic factors associated with college students of health sciences from a public university. http://search.ebscohost.com/login.aspx?direct=true\&db=a9h\&AN=82115757\&la http://search.ebscohost.c
$\mathrm{ng}=\mathrm{es} \&$ site=ehost-live

14. Halperin SJ, Henderson MN, Prenner S, Grauer JN. Prevalence of anxiety and depression among medical students during the covid-19 pandemic: A crosssectional study. J Med Educ Curric Develop. 2021;8:1-7. https://doi. sectional study. J Med Educ
org/10.1177/2382120521991150

15. World Health Organisation (WHO). Health environments for children: Initiating an alliance for Action. Geneva: WHO; 2002.

16. Horton BW, Snyder CS. Wellness: Its impact on student grades and implications fo business. J Hum Resour Hosp Tour. 2009;8(2):215-233. https://doi org/10.1080/15332840802269858

17. Maharaj A. Wellness factor impacting student academic performance from a higher education perspective. Educor Multidiscip J. 2018;1(1):69-85. https://doi. org/10.1002/he.20304
18. Gleason BK, Hays DG. A phenomenological investigation of wellness within counselor education programs. Couns Educ Superv. 2019:58(3):177-194. https:// counselor education programs.
doi.org/10.1002/ceas.12149

19. Beck JA, Harmon J, Kornegay E, Phillips C. Student wellness: Stress in dental hygiene programs. J Dent Hyg. 2020;94(5), 55.

20. Wolf CP, Thompson IA, Smith-Adcock S. Wellness in counselor preparation Promoting individual well-being. J Individ Psychol [serial online]. 2012 [cited 2014 Jun 15];68(2):164-181. Available from: http://proxygsu-col1.galileo.usg.edu/ login?url=http://search.ebscohost.com/login. aspx?direct=true\&db=a9h\&AN=76 259602\&site=ehost-live

21. Goss HB, Cuddihy TF, Michaud-Tomson L. Wellness in higher education: A transformative framework for health related disciplines. Asia Pac J Health Sport Phys Educ. 2010;1(2):29-36. https://doi.org/10.1080/18377122.2010.9730329

22. Lockwood P, Wohl R. The impact of a 15-week lifetime wellness course on behavior change and self-efficacy in college students. Coll Stud J. 2012;1(1):628-642.

23. Shalala Donna E. Prescription for change: Health, wellness and higher education. Presidency [serial online]. 2010 [cited 2014 Jun 15];13(3):18-23. Available from: http://0-web.b.ebscohost.com.ujlink.uj.ac.za/ehost/pdfviewer/pdfviewer? vid=32\&sid=85923f66-0915-4f0a-95e6-5883984a5ea8@sessionmgr120\&hid=102

24. Lenz AS, Sangganjanavanich VF, Balkin RS, Oliver M, Smith RL. Wellness model of supervision: A comparative analysis. Couns Educ Superv. 2012;51(3):207-221. https://doi.org/10.1002/j.1556-6978.2012.00015.x

25. Dixon $D$, Johnston $M$. What competences are required to deliver person-person behaviour change interventions: Development of a health behaviour change competency framework. Int J Behav Med. 2021;28:308-317. https://doi. competency framework. Int J
org/10.1007/s12529-020-09920-6

26. Habib S, Riaz MN, Akram M. Emotional intelligence as predictor of life satisfaction among nurses: Mediating role of spiritual wellness. FWU J Soc Sci [serial online]. 2012 [cited 2018 Feb 16];6(1):73-78. Available from: http://search.ebscohost. com/login.aspx?direct=true\&db=a9h\&AN=78549999\&site=ehost-live

27. McKenney S, Reeves TC. Conducting educational design research [homepage on the Internet]. Routledge, 2013 [cited 2016 Jan 28]; p. 256. Available from: https:// books.google.com/books?hl=en\&lr=\&id=CpcnCEQIfLLC\&pgis=1

28. Seeman MV. Handbook of girls' and women's psychological health: Gender and well-being across the life-span. Psychol Med. 2006;36(7):1043-1044.

29. Gerhardt M. Teaching self-management: The design and implementation of selfmanagement tutorials. J Educ Bus. 2007;83(1):11-17. https://doi.org/10.3200/ JOEB.83.1.11-18

30. Omisakin FD, Ncama BP. Self, self-care and self-management concepts: Implications for self-management education. Educ Res. 2011;2(12):1733-1737.

31. Grant AM. Is it time to regrow the grow model? Issues related to teaching coaching session structure. Coach Psychol. 2011;7(2):118-126.

32. Orem SL, Binkert J, Clancy AL. Appreciative coaching. J Chem Inf Model. 2013;52:1689-1699.

33. Roslender R, Stevenson J, Kahn H. Employee wellness as intellectual capital: An accounting perspective. J Hum Resour Cost Account. 2006;10(1):48-64. https:// doi.org/10.1108/14013380610672675

34. Karpicke JD. Concept mapping. In: The Sage encyclopedia of educational research, measurement, and evaluation. 2018 [cited 2021 Aug 18]. Available from: https:// doi.org/10.4135/9781506326139

35. Cooperrider D, Whitney DD, Stavros J. The appreciative inquiry handbook: For leaders of change. San Fransisco: Berrett-Koehler Publishers; 2008

36. Taylor SJ, Bogdan R, DeVault M. Introduction to qualitative research methods: A guidebook and resource. Hoboken, NJ: John Wiley and Sons; 2015.

37. Krueger RA, Casey MA. Focus groups: A practical guide for applied research Review literature and Arts of the Americas [homepage on the Internet]. 2000 [cited 2013 Oct 4];22:129-152. Available from: http://books.google.com/books?h [cited 2013 Oct 4];22:129-152. Availab1

38. Myers J, Sweeney T. The indivisible self: An evidence-based model of wellness. J Individ Psychol [serial online]. 2004 [cited 2014 Jun 21]:60(3):234-245. Available from: http://libres.uncg.edu/ir/uncg/f/j_myers_indivisible_2004.pdf

39. Given LM. The Sage encyclopedia of qualitative research methods. Cambridge: The MIT Press, 2008; p. 1043.

40. Rolls L, Relf M. Bracketing interviews: Addressing methodological challenges in qualitative interviewing in bereavement and palliative care. Mortality. 2006;11(3):286-305. https://doi.org/10.1080/13576270600774893

41. Creswell JW. Research design: Qualitative, quantitative, and mixed methods approaches [homepage on the Internet]. Sage, 2013 [cited 2016 Jan 28]; p. 304. Available from: https://books.google.com/books?id=EbogAQAAQBAJ\&pgis=1

42. Bahrami Z, Cranney J. Integrated conative model of well-being: From motives to well-being. J Happiness Stud. 2017;19:961-981. https://doi.org/10.1007/s10902-
017-9845-2 